\title{
Fusobacterium nucleatum and oral cancer: a critical review
}

\author{
Emily Mcllvanna', Gerard J. Linden², Stephanie G. Craig ${ }^{1,3}$, Fionnuala T. Lundy $4^{4^{*}}$ and Jacqueline A. James ${ }^{1,3,5^{*}}$ (D)
}

\begin{abstract}
There is a growing level of interest in the potential role inflammation has on the initiation and progression of malignancy. Notable examples include Helicobacter pylori-mediated inflammation in gastric cancer and more recently Fusobacterium nucleatum-mediated inflammation in colorectal cancer. Fusobacterium nucleatum is a Gramnegative anaerobic bacterium that was first isolated from the oral cavity and identified as a periodontal pathogen. Biofilms on oral squamous cell carcinomas are enriched with anaerobic periodontal pathogens, including $F$. nucleatum, which has prompted hypotheses that this bacterium could contribute to oral cancer development. Recent studies have demonstrated that $F$. nucleatum can promote cancer by several mechanisms; activation of cell proliferation, promotion of cellular invasion, induction of chronic inflammation and immune evasion. This review provides an update on the association between F. nucleatum and oral carcinogenesis, and provides insights into the possible mechanisms underlying it.
\end{abstract}

Keywords: Fusobacteria, F. nucleatum, Carcinogenesis, Oral cancer, OSCC

\section{Background}

Head and neck cancer was identified as the seventh most common cancer worldwide in 2018 , with 890,000 new cases and 450,000 deaths being reported [1]. Oral squamous cell carcinoma (OSCC) is the most prevalent subgroup of head and neck cancer and represents a major cause of morbidity and mortality worldwide. OSCC has a remarkably high prevalence in some populations, particularly in Southern Asia and the Pacific islands, and is a leading cause of cancer death among men in India and Sri Lanka [1]. Some OSCCs arise from oral potentially malignant disorders (OPMDs) such as leukoplakia and erythroplakia, whilst others arise de novo [2]. Established risk factors for OSCC include smoking and oral exposure to tobacco, which in South Asia may be associated with habitual use of betel quid. The consumption of

\footnotetext{
*Correspondence: F.Lundy@qub.ac.uk; J.James@qub.ac.uk

${ }^{4}$ Wellcome-Wolfson Institute for Experimental Medicine, Queen's University Belfast, Belfast, Northern Ireland, UK

'Patrick G Johnson Centre for Cancer Research, Queen's University Belfast, Belfast, Northern Ireland, UK

Full list of author information is available at the end of the article
}

alcohol is a recognised risk factor and has a synergistic interaction with smoking [3]. Although OSCC predominantly affects males in their sixth or seventh decade, the incidence of OSCC in women and in people under 40 is increasing [4]. Moreover, emerging evidence suggests that a subgroup of those presenting with OSCC have never smoked or drank alcohol [5]. This implies that there are other unknown aetiological factors that are associated with the development of OSCC.

In recent years it has been shown that specific infectious agents play a key role in the development of certain cancer types [6]. In the context of head and neck cancer, human papilloma virus (HPV) type 16 has been identified as a causative agent for oropharyngeal cancer [7]. HPV-induced oropharyngeal tumours are considered a separate disease entity which have a better prognosis compared to HPV-ve tumours [7]. The favourable outcome of HPV + ve compared with HPV-ve oropharyngeal tumours is so substantial that the tumour-nodemetastasis (TNM) staging for HNSCC was adapted in the eighth edition to include p16 immunostaining as a

(c) The Author(s). 2021 Open Access This article is licensed under a Creative Commons Attribution 4.0 International License, which permits use, sharing, adaptation, distribution and reproduction in any medium or format, as long as you give appropriate credit to the original author(s) and the source, provide a link to the Creative Commons licence, and indicate if changes were made. The images or other third party material in this article are included in the article's Creative Commons licence, unless indicated otherwise in a credit line to the material. If material is not included in the article's Creative Commons licence and your intended use is not permitted by statutory regulation or exceeds the permitted use, you will need to obtain permission directly from the copyright holder. To view a copy of this licence, visit http://creativecommons.org/licenses/by/4.0/ The Creative Commons Public Domain Dedication waiver (http://creativecommons.org/publicdomain/zero/1.0/) applies to the data made available in this article, unless otherwise stated in a credit line to the data. 
surrogate marker for HPV status [7]. The percentage of head and neck cancers diagnosed as HPV-positive oropharyngeal cancers in the United States rose from 16.3\% in the 1980 s to more than $72.7 \%$ in the 2000 s [8]. The oral mucosa is exposed to a huge array of microorganisms that collectively comprise the oral microbiome. Studies using both traditional culture and culture independent molecular approaches have identified around 700 predominant bacterial species in the oral cavity [9]. The presence of several distinct habitats, including the hard non-shedding tooth surfaces in the oral cavity, presents unique microbial niches that can communicate oral microbiome changes at micron-scale gradients with each other via saliva for both short and long range microbial interactions [9]. The accumulation and maturation of dental plaque on tooth surfaces can lead to gingivitis, which is reversed on plaque removal [10]. In some cases, persistent accumulation of dental plaque biofilms and associated chronic inflammation causes periodontitis, resulting in irreversible destruction of tooth supporting tissues [10]. In recent years there has been a reappraisal of our understanding of the bacterial pathogenesis of periodontitis. It is now accepted that shifts in the microbiome induced by inflammation favour overgrowth of certain commensals and altered expression of virulence factors, rather than the introduction of new pathogenic species $[11,12]$. Inflammation has long been suspected to play a major role in the pathogenesis of cancer, and it has been hypothesised that commensal microorganisms might provide the link between chronic inflammation and carcinogenesis [13]. Interestingly, several studies have identified periodontitis as an independent risk factor for oral cancer development [14-17]. One microorganism that is a key player in the development and maturation of biofilms that accompany dysbiotic changes in dental plaque is Fusobacterium nucleatum [10].

Landmark publications in 2012, from two independent groups, reported that $F$. nucleatum infection was prevalent in human colorectal carcinoma (CRC) $[18,19]$. Subsequently there has been extensive research into $F$. nucleatum as a risk factor for CRC however, its putative involvement in oral cancer has received less attention. This review will focus on a possible role for F. nucleatum in oral cancer with discussion of possible mechanisms that this bacterium could utilise to promote neoplastic change in the oral mucosa. It will also identify questions raised by the potential involvement of this common constituent of the oral microbial flora in oral carcinogenesis.

\section{Fusobacterium nucleatum}

F. nucleatum is a Gram-negative filamentous spindleshaped rod that is a common inhabitant of the oral flora.
It has not traditionally been considered as a pathogenic species in the oral cavity, although it has an emerging role in driving inflammation. There is speculation that it can act as an opportunist pathogen in relation to extraoral sites, as it has been implicated in diseases such as appendicitis, brain abscesses, and chorioamnionitis [20]. However further discussion of this, except for involvement in CRC, is beyond the scope of this review. F. nucleatum is the second most frequently recovered species in dental plaque biofilms associated with health [12]. F. nucleatum is termed a core species in oral biofilms as its proportions remain unchanged, at about $25 \%$, in both health- and disease-associated dental plaque. However, this should be interpreted in the context of a 3-log increase in the total microbial load that occurs in periodontal inflammation [12]. F. nucleatum is a pivotal 'bridging' bacterium that acts in a supportive role by co-aggregating with both the early (Streptococcal spp.) and late colonizers, such as Porphyromonas gingivalis, thereby guiding the architecture of the dental plaque biofilm [21]. Its long rod shape is central to establishing structural relationships that are critical to polymicrobial biofilms and interactions between microorganisms [20]. F. nucleatum can bind and/or invade diverse cell types including oral, colonic and placental epithelial cells, T-cells, keratinocytes and macrophages through the expression of adhesins such as FadA and Fap2 $[22,23]$. These adhesins are also thought to have a putative role in carcinogenesis [20].

\section{F. nucleatum in gastrointestinal cancer}

Many studies have shown an enrichment of $F$. nucleatum in CRC compared to the levels in normal adjacent tissue and in healthy controls [19, 24-28]. A recent meta-analysis indicated that the odds of $F$. nucleatum DNA being detected were higher in colorectal tumour tissue compared with adjacent healthy tissue and healthy tissue from controls [29]. F. nucleatum DNA was also higher in colorectal polyp tissue compared with healthy tissue from controls [29]. Studies have shown that $F$. nucleatum is abundant in faecal samples from patients with CRC [30-32]. Meta-analysis found the pooled odds of $F$. nucleatum positivity were higher in faecal samples from patients with CRC compared with healthy controls; higher in patients with CRC compared with individuals with colorectal polyps; but not from individuals with colorectal polyps compared with healthy controls [29]. F. nucleatum has been isolated from cancers at other sites along the digestive tract, namely the pancreas [33], oesophagus [34, 35] and stomach [35, 36]. F. nucleatum has also recently been implicated in the growth and progression of breast cancer [37].

F. nucleatum was previously regarded as a passive bacterium in the gastrointestinal tract. However, it is now 
recognised that $F$. nucleatum infection can induce a series of specific tumour molecular events in colorectal cancer, including $\mathrm{CpG}$ island methylator phenotype, microsatellite instability and genetic mutations in $B R A F$ and TP53 [24, 26, 38]. Moreover, many of these studies have identified that the presence of intra-tumoral $F$. nucleatum is associated with worse survival [26-28, 33, 35, 38-46]. It has also been observed that F. nucleatum infection is associated with worse clinicopathological features such as larger tumours, poorer differentiation, lymph node and distant metastases, advanced tumour stage and deeper tumour invasion [19, 24, 27, 40-42].

Interestingly, it has been shown that strains of $F$. nucleatum in CRC were identical to strains of this species isolated from the mouth, suggesting that the intratumoral F. nucleatum may have originated from the oral cavity [47]. If F. nucleatum from the oral cavity has a role in cancer development at extra-oral sites, then it is reasonable to hypothesise that this bacterium could contribute to carcinogenesis in the oral cavity itself.

\section{F. nucleatum in OSCC}

Several studies aimed to identify the microbial species present within OSCC tumour tissue compared with nontumorous control materials using either culture approaches, 16 s rRNA sequencing or next generation sequencing (NGS), and these studies have already been previously reviewed [4852]. In 1998, the first association study by Nagy et al. found that levels of Porphyromonas and Fusobacterium were significantly higher in OSCC than in normal tissue [53]. However, more recent studies have profiled tumour-specific microbiomes at the species level using NGS which has facilitated the detection of $F$. nucleatum in oral cancer samples [54-62].

Using NGS, Al-Hebshi and colleagues found that F. nucleatum was the most abundant species in OSCC samples, followed by Pseudomonas aeruginosa [55]. This study was also the first to report on the potential functional role of the OSCC-associated bacteriome as it found that genes involved in bacterial mobility, flagellar assembly, bacterial chemotaxis and lipopolysaccharide (LPS) synthesis were enriched in the tumours [55]. The latter being particularly relevant to the virulence of Gram-negative bacteria, such as F. nucleatum. Recently, Zhang et al. confirmed that the abundance of $F$. nucleatum was significantly increased in OSCC [56]. Furthermore, this study corroborated the finding that the abundance of genes involved in bacterial chemotaxis, flagellar assembly and importantly, LPS biosynthesis, were significantly increased in the OSCC group [56]. Similarly, Zhao and colleagues identified $F$. nucleatum to be one of three Fusobacterium species significantly enriched in the oral cancer group, whereas $P$. gingivalis did not differ in abundance between groups [57]. Additionally, several operational taxonomic units associated with Fusobacterium were highly involved in OSCC and demonstrated good diagnostic power [57]. Perera and colleagues identified enrichment of the LPS biosynthesis pathway in OSCC tissue and speculated that the 'Fusobacterium oral taxon 204' detected in their study may have been a functional equivalent to F. nucleatum [59]. Yost and colleagues profiled RNA expression in the oral microbiome in OSCC and reported that Fusobacteria had a higher number of transcripts at tumour sites compared with adjacent non-affected sites or healthy controls. Specifically, $F$. nucleatum showed the highest upregulation of putative virulence factors for tumour sites. They concluded that Fusobacteria was the phylogenetic group responsible for the upregulation of virulence factors in the oral microbiome of OSCC patients [62].

To date, only one systematic review and meta-analysis on the presence of Fusobacterium in oral cancer/head and neck cancer has been completed [63]. This study concluded that Fusobacterium is present and in higher abundance in oral cancer/head and neck cancer samples when compared to non-cancer samples, suggesting that Fusobacterium could contribute to oral cancer/head and neck cancer development [63]. However, it is also possible that tumour colonisation by $F$. nucleatum reflects its ability to exploit and replicate effectively in the hypoxic tumour microenvironment. Perhaps dispelling this hypothesis is the finding that OPMDs are also enriched with F. nucleatum $[64,65]$. This evidence that F. nucleatum colonisation begins early in the process of malignant transformation supports a potential role for microbiome changes in the pathogenesis of the disease.

Two recently published studies have examined the prognostic effect of $F$. nucleatum in oral/head and neck cancer, and the findings are summarised in Table $1[66,67]$. Neuzillet et al found that F. nucleatum was significantly associated with improved overall survival, relapse-free survival and metastasis-free survival in their merged OSCC cohort [66]. Similarly Chen et al found that F. nucleatum enrichment in HNSCC tumour tissues was significantly associated with better cancer-specific survival and a lower rate of relapse [67]. These findings are unexpected given its association with poor prognosis in other cancer types. F. nucleatum-associated OSCC was more frequent in HPV-ve tumours and in older patients lacking the traditional risk factors of alcohol [66] and smoking [67]. F. nucleatum-positivity was also associated with lower tumour (pT) stage [67] and lower nodal ( $\mathrm{pN})$ stage [66]. Interestingly, the association of low $\mathrm{pT}$ or $\mathrm{pN}$ stage with $F$. nucleatum positivity allowed the identification of a patient subgroup with remarkably good prognosis [66].

\section{Potential carcinogenesis mechanisms linked to $F$. nucleatum}

Until recently, the only experimental evidence that $F$. nucleatum could induce malignant change in the oral cavity was presented by Binder Gallimindi et al. who 
Table 1 Summary of publications reporting on the prognostic impact of $F$. nucleatum in oral cancers

\begin{tabular}{|c|c|c|c|c|c|c|c|}
\hline Author & Reference & $\begin{array}{l}\text { Specimen } \\
\text { type }\end{array}$ & $\begin{array}{l}\text { Detection } \\
\text { method }\end{array}$ & $\begin{array}{l}\text { Number } \\
\text { of cases }\end{array}$ & $\begin{array}{l}\text { F. } \\
\text { nucleatum } \\
\text { detection } \\
\text { rate }\end{array}$ & $\begin{array}{l}\text { Prognostic } \\
\text { impact of } \\
F . \\
\text { nucleatum } \\
\text { detection }\end{array}$ & $\begin{array}{l}\text { Molecular and clinicopathological associations } \\
\text { with tumour F. nucleatum positivity }\end{array}$ \\
\hline $\begin{array}{l}\text { Neuzillet } \\
\text { et al } \\
(2021)\end{array}$ & 66 & $\begin{array}{l}\text { Fresh } \\
\text { frozen } \\
\text { OSCC }\end{array}$ & qPCR & 151 & $\begin{array}{l}82.1 \% \mathrm{Fn}- \\
\text { positive } \\
(124 / 151)\end{array}$ & $\begin{array}{l}\text { Better OS, } \\
\text { RFS and } \\
\text { MFS }\end{array}$ & $\begin{array}{l}\text { Older (> } 56 \text { years), non-drinkers, low pN stage. Low RNA } \\
\text { levels of M2 macrophages (CD163), CD4 lymphocytes, fibro- } \\
\text { blasts (PDGFRß), TLR4, OX40 ligand (TNFSF4) High levels of } \\
\text { TNFSF9 and IL-1ß }\end{array}$ \\
\hline $\begin{array}{l}\text { Chen } \\
\text { et al } \\
\text { (2020) }\end{array}$ & 67 & $\begin{array}{l}\text { Fresh } \\
\text { frozen } \\
\text { HNSCC }\end{array}$ & $\mathrm{qPCR}$ & 68 & $\begin{array}{l}55.8 \% \text { Fn- } \\
\text { high } \\
(38 / 68)\end{array}$ & $\begin{array}{l}\text { Better CSS } \\
\text { and RFS }\end{array}$ & $\begin{array}{l}\text { Non-smokers, lower tumour stage, hypermethylation of } L X N \\
\text { and SMARCA2 genes }\end{array}$ \\
\hline
\end{tabular}

Abbreviations: CIMP-H, CpG island methylator phenotype high; CSS, cancer-specific survival; ddPCR, droplet digital polymerase chain reaction; DFS, disease-free survival; FFPE, formalin-fixed paraffin-embedded; MSI-H, microsatellite instability-high; OS, overall survival; qPCR, quantitative polymerase chain reaction; RFS, recurrence-free survival; RT-qPCR, real time quantitative polymerase chain reaction

showed that $P$. gingivalis and $F$. nucleatum could promote carcinogenesis in a chemically-induced murine model of OSCC [68]. Both Gram-negative anaerobic pathogens could stimulate tumorigenesis via direct interaction with oral epithelial cells through Toll-like receptors (TLR) and augmented signalling via the IL-6STAT3 axis [68]. Infection with $F$. nucleatum induced key molecular players, such as cyclin D1 and matrix metalloproteinase-9 (MMP-9), which are involved in oral tumour growth and invasiveness. Tumours from infected mice were 2.5 times larger and were significantly more invasive compared to non-infected mice [68]. A more recent study by Harrandah et al. supported these findings in a similar oral tumour murine model [69]. Infected oral cancer cells had upregulated expression levels of MMP1, MMP9, and IL-8. The expression of cell survival markers MYC, JAK1, and STAT3 and epithelialmesenchymal transition markers ZEB1 and TGF- $\beta$ were also significantly elevated [69]. Additionally, mice infected with $F$. nucleatum developed significantly larger and more numerous lesions compared to uninfected controls [69]. Both studies identified the signal transducer and activator of transcription-3 (STAT3) signalling pathway as being a key mediator in fostering oral tumorigenesis. STAT3 signalling promotes initiation and progression of cancer by controlling genes responsible for suppressing apoptosis and driving proliferation, angiogenesis, metastasis and invasion (Fig. 1) [68].

Most of the research on mechanisms linking F. nucleatum with carcinogenesis has focused on how F. nucleatum contributes to CRC, therefore conclusions relating to its mechanistic involvement in oral carcinogenesis are tentative. However, the mechanisms that have been identified through which $F$. nucleatum promotes neoplastic change in the colon could be applicable at other mucosal sites and so they merit discussion in the context of OSCC.

\section{Binding and localization}

Recent evidence has shown that F. nucleatum attaches via its Fap2 adhesin, to an oligosaccharide called GalGalNAc that is overexpressed on cancer cells [37, 70]. Expression of Gal-GalNAc can be detected using the lectin Peanut Agglutinin (PNA) which is specific for this oligosaccharide [71]. It has been shown that PNA staining, and thus Gal-GalNAc levels, correlates with human breast cancer progression. Furthermore, the occurrence of $F$. nucleatum gDNA in breast cancer samples correlates with high Gal-GalNAc levels [37]. Fap2-dependent binding of $F$. nucleatum to breast and colon tumours

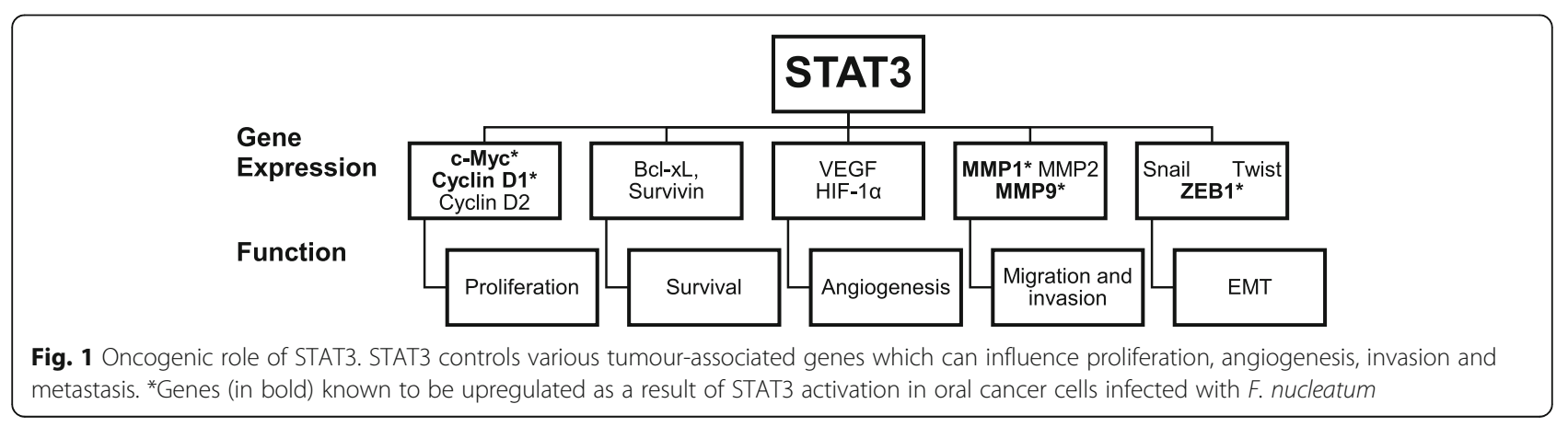


has been demonstrated $[37,70]$. No studies to date have investigated if $F$. nucleatum colonisation of OSCC tissue occurs via a Fap2/Gal-GalNAc dependent mechanism. However, PNA has been shown to preferentially bind to OSCC tissue, which is indicative of Gal-GalNAc expression. Furthermore, one study found that PNA showed weak binding to normal oral mucosal cells, intermediate binding to dysplastic cells and strong binding to malignant squamous cell carcinoma [72]. This coincides with the finding that $F$. nucleatum abundance increases along the pathway from normal tissue to dysplasia to malignancy $[64,65]$.

\section{Co-aggregation with other microorganisms}

F. nucleatum is a key 'bridging' organism between early and late colonisers and its outer membrane adhesin Fap2 is partly responsible for facilitating multispecies biofilm formation [23] F. nucleatum is always present when $P$. gingivalis is reported within oral biofilms, suggesting that it precedes this species and is required for its colonization [21]. P. gingivalis is an acid-sensitive bacterium, however $F$. nucleatum can produce ammonia by fermenting glutamate and aspartate in order to provide a more neutral environment conducive for $P$. gingivalis colonisation [73]. A study by Katz et al. was the first to identify $P$. gingivalis in OSCC tissue [74]. Further studies have suggested that $P$. gingivalis could also contribute to OSCC and digestive tract cancer development [75]. It is possible that $F$. nucleatum and $P$. gingivalis work co-operatively to promote neoplastic changes by triggering chronic inflammation. Indeed, Binder Gallimindi et al. showed that a mixture of $F$. nucleatum and $P$. gingivalis significantly stimulated in vitro proliferation of human OSCC cells [68]. However, a more recent study by Harrandah et al. showed that infection of oral cancer cells with $F$. nucleatum alone had comparable or greater effects than a combination of four periodontal pathogens [69].

Candida albicans is an opportunistic pathogenic yeast that is commonly found in the gastrointestinal tract and mouth [76]. Recent mycobiome studies have shown increased abundance of several fungal species including $C$. albicans in OSCC [76]. It is well established that Candida species in the oral cavity possess the enzyme alcohol dehydrogenase responsible for catalysing the production of acetaldehyde, a potent carcinogen, from alcohol [48]. It has been shown that $F$. nucleatum coaggregates with Candida species and this can facilitate colonisation [77]. Amer et al. reported that Candida colonisation of oral leukoplakia was associated with increased levels of $F$. nucleatum [64]. It is possible that $F$. nucleatum may indirectly act to increase oral cancer risk by increasing the exposure of oral mucosa to acetaldehyde produced by Candida species.

\section{Activation of cell proliferation}

Cancer is, at its simplest, uncontrolled cell growth, and $F$. nucleatum has been shown to influence the proliferation of cancer cells by interacting with endothelial cadherin (E-cadherin) [78, 79]. Fusobacterial FadA binds to E-cadherin which is expressed on the surface of the host cell membrane [80]. E-cadherin is a tumour suppressor which acts through $\beta$-catenin. Interaction of fusobacterial FadA with E-cadherin activates $\mathrm{WNT} / \beta$-catenin signalling, resulting in cell proliferation with increased expression of oncogenic and inflammatory genes $[78,81]$.

Similarly, F. nucleatum has been shown to increase CRC proliferation in a mouse xenograft by activating Toll-Like Receptor 4 (TLR4) signalling to MYD88, leading to activation of the nuclear factor $N F K B$ and increased expression of miR21; this miRNA reduces levels of the RAS GTPase RASA1 which is responsible for controlling cell proliferation and differentiation [82].

Cell cycle progression is facilitated by cyclindependent kinases that are activated by cyclins. F. nucleatum infection has been associated with the activation of cyclin D1, which facilitates intestinal tumorigenesis [81, 83]. In OSCC, both $F$. nucleatum and $P$. gingivalis were shown to be capable of significantly stimulating OSCC cell proliferation by upregulating cyclin D1 and c-Myc $[68,69]$. Bacterial activation of TLR4 led to an increased expression of interleukin-6 (IL-6) which in turn activated STAT3, a key signalling molecule responsible for regulating cyclin D1 and c-Myc $[68,69]$. Moreover, F. nucleatum was shown to cause DNA damage and promote cell proliferation in oral cancer cells by decreasing p27 expression, a cyclin-dependent kinase inhibitor, and accelerating the cell cycle [84]. Additionally, F. nucleatum downregulated the DNA repair proteins Ku70 and p53, thereby weakening cell repair ability [84].

A recent study identified that enrichment of $F$. nucleatum in HNSCC was associated with host gene promoter methylation, including hypermethylation of tumour suppressor genes $L X N$ and SMARCA2 [67]. SMARCA2 is a gene involved in ATP-dependent chromatin remodelling related to DNA repair and replication. This suggests that F. nucleatum infection may cause cell proliferation through epigenetic silencing [67].

\section{Induction of inflammation}

The pro-inflammatory potential of $F$. nucleatum is well documented, as it is known to facilitate reactive oxygen species (ROS) generation and cytokine production [85-89]. Chronic inflammation plays a pivotal role in carcinogenesis and may explain the strong association between periodontitis and higher risk of OSCC [48]. F. nucleatum has been found to be associated with high cytokine levels in CRC and OSCC, creating an inflammatory microenvironment supportive of tumour progression $[18,68,69]$. LPS, which is found in the 
outer membrane of $F$. nucleatum, activates the TLR4mediated NF-kB signalling pathway to produce proinflammatory cytokines such as IL-6, IL-8 and tumour necrosis factor alpha [68].

\section{Anti-tumour immune response}

F. nucleatum has been shown to recruit myeloid-derived suppressor cells into the tumour microenvironment in the ApcMin/+ mouse model [18]. Myeloid-derived suppressor cells can inhibit $\mathrm{T}$-cell proliferation and induce $\mathrm{T}$-cell apoptosis [18]. This is consistent with a recent finding of the inverse association between the amount of F. nucleatum and the density of CD3 and CD4 T-cells in colorectal and breast cancer tissue [37, 90, 91]. A significant negative association between $F$. nucleatum load in OSCC and markers of B lymphocytes, CD4 T helper lymphocytes, M2 macrophages and fibroblasts has also been observed [66]. F. nucleatum inhibitory protein can also inhibit human T-cell activation by arresting cells in the G1 phase of the cell cycle [92]. The Fusobacterial Fap2 adhesin binds and activates the T-cell immunoreceptor with Ig and ITIM domains (TIGIT), which is an immunoregulatory signalling receptor in T-cells and natural killer (NK) cells [93]. This Fap2-TIGIT interaction protects both $F$. nucleatum and nearby tumour cells from being killed by immune cells [93]. Local immune suppression can also occur because Fap2 and RadD outer membrane proteins of $F$. nucleatum induce cell death in lymphocytes [94]. F. nucleatum also exerts an immunosuppressive effect by promoting M2 polarization of macrophages in F. nucleatum-related CRCs, possibly through the TLR4/IL-6/p-STAT3/c-MYC signalling pathway [95].

\section{Cell migration and invasion}

Matrix metalloproteinases (MMPs) are a family of zincdependent endopeptidases collectively capable of degrading all components of the extracellular matrix (ECM) [96]. MMPs play a role in pathological conditions with excessive degradation of ECM, including tumour invasion and metastasis [96]. Both $P$. gingivalis and $F$. nucleatum can produce MMPs via different mechanisms and so promote cancer cell invasion and metastasis [97100]. In OSCC, it has been observed that exposure to $P$. gingivalis and $F$. nucleatum resulted in the induction of MMP-1 and MMP-9 [68, 69]. Similarly, AT3 mouse mammary carcinoma cells incubated with $F$. nucleatum also exhibited an overexpression of MMP-9 [37].

Epithelial-mesenchymal transition (EMT), is defined as the process by which epithelial cells adopt a mesenchymal phenotype and is a phenomenon observed in cancer development and progression [101]. In general, cells proceeding to EMT exhibit down-regulation of epithelial markers such as E-cadherin and up-regulation of mesenchymal markers, including neural-cadherin (Ncadherin) and Vimentin [102]. This switch in cell differentiation behaviour is controlled by a group of transcription factors including the zinc-finger E-box-binding homeobox 1 and 2 proteins (ZEB1/2), SNAIL and TWIST. High levels of $F$. nucleatum in CRC are negatively correlated with E-cadherin expression but positively correlated with expression of N-cadherin [45]. Similarly, exposure of OSCC cell lines to F. nucleatum has been associated with a significant decrease in transcription of E-cadherin and the upregulation of $\mathrm{N}$ cadherin, vimentin and Snail [103, 104].. F. nucleatum can upregulate the expression of ZEB1 in oral cancer cells to induce this mesenchymal state, [66] a mechanism which has previously been identified in H. pylori-infected gastric epithelial cells [105].

\section{Possible implications for OSCC management}

Since the discovery that $F$. nucleatum is an important biomarker for CRC, particularly a prognostic one, there has been considerable research surrounding potential therapeutic and prevention strategies to address the association of $F$. nucleatum with tumorigenesis. A recent study showed that treatment of mice bearing a colon cancer xenograft with the antibiotic metronidazole successfully decreased Fusobacterium load, cancer cell proliferation and tumour growth [46]. Similarly, in an AT3 orthotropic mammary cancer model, metronidazole prevented tumour enlargement and lung metastasis in mice inoculated with F. nucleatum [37]. However, antibiotic administration is associated with issues including generation of resistant strains, misbalancing the resident body flora and inducing hypersensitivity reactions. It is possible that some of these issues could be mitigated by using topical metronidazole in the oral cavity for $F$. nucleatum-positive OSCC. Oral rinses could potentially be used as non-invasive samples to reflect tissue microbial composition for diagnostics, as a recent study noted similar relative abundances of bacteria across both oral cancer tissue samples and oral rinses obtained from the same patients [67].

A recent study investigating the role of Treponema denticola in promoting oral cancer development showed that the three periodontal pathogens ( $T$. denticola, $P$. gingivalis and $F$. nucleatum) enhanced OSCC cell migration, invasion, tumorsphere formation, and tumorigenesis in vivo and that Nisin inhibited these pathogen-mediated processes [106]. Nisin is a bacteriocin produced by Gram-positive Lactococcus and Streptococcus species and is a commonly used food preservative. Nisin has been previously shown to attenuate oral tumorigenesis and thus has therapeutic potential as an antimicrobial and anti-tumorigenic agent [106, 107].

Given the global health burden of colorectal cancer, and other conditions that have been associated with $F$. 


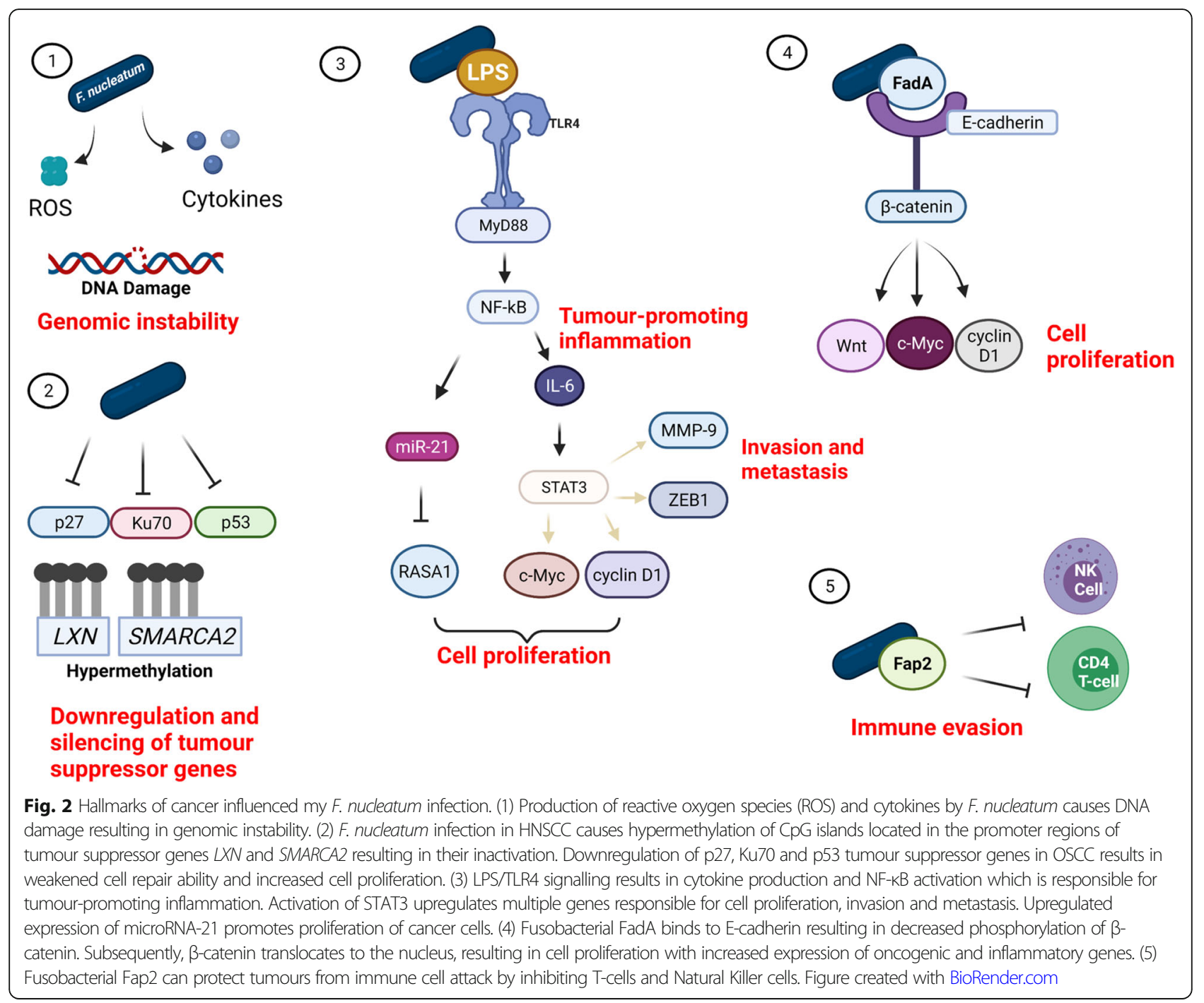

nucleatum, the development of a vaccine warrants consideration [20]. A vaccine targeting FomA, an outer membrane protein of $F$. nucleatum responsible for bacterial co-aggregation and biofilm formation, has been tested as an agent to combat periodontal infection and halitosis [108]. However, it is not known whether recipients of this vaccine had a lower incidence of cancer attributable to F. nucleatum infection. A recent study investigating immunization with the alkyl hydroperoxide reductase subunit $C$ from $F$. nucleatum found that vaccination lowered the levels of the bacterium in intestinal tissues and elicited IgA and IgG responses in mice [109]. Furthermore, clinical isolates of fusobacterial strains naturally lacking Fap2 or inactivated Fap2 mutants, showed reduced binding to Gal-GalNAc on colorectal and breast cancer cells $[37,70]$. Therefore, vaccines targeting Fusobacterial Fap2 could theoretically reduce fusobacteria colonisation and potentiation of oral cancer.

\section{Conclusions}

Despite a wealth of research on $F$. nucleatum over several years, many unanswered questions remain. One key area of controversy is whether F. nucleatum is an active conductor of neoplastic change in epithelial cells or a passive passenger that colonises due to favourable conditions provided by the tumour milieu. F. nucleatum has been primarily characterised as a bridging organism in the assembly and architecture of multi species biofilms however, more recent studies have identified other active roles. The potential for F. nucleatum to act as a carcinogen is credible, as it has been shown to promote inflammation and suppress local immune responses. One intriguing question is why a microorganism that is ubiquitous in the mouth throughout life might only very occasionally become carcinogenic? The answer to this likely involves changes within the oral microbiome within the context of host factors such as genetics, oral 
hygiene behaviour, nutrition, age and exposure to risk factors such as tobacco and alcohol. A recent study found that tobacco, irrespective of the mode of use, created an oral microenvironment favouring anaerobes such as Fusobacterium [110].

A "two-hit" model in carcinogenesis, with somatic mutations serving as the first hit and F. nucleatum as the second hit exacerbating cancer progression after benign cells become cancerous, has previously been proposed [80]. Inflammatory cytokines and reactive oxygen species produced as a result of F. nucleatum infection could facilitate cancer development by inducing mutations, genomic instability and epigenetic alterations [48]. Cytokines can then activate key transcription factors such as NF-kB and STAT3 within oral pre-malignant cells which subsequently promote pro-malignant processes such as proliferation, invasion and metastasis.

F. nucleatum affects many of the accepted hallmarks of cancer [110]. F. nucleatum infection can induce genomic instability by causing DNA damage; sustain proliferative signalling via LPS/TLR4 and FadA/E-cadherin signalling pathways; downregulate and silence tumour suppressor genes; avoid immune destruction by inhibiting T-cell and NK cell activities; generate pro-tumour inflammation by activating NF- $\mathrm{kB}$ signalling; and cause invasion and metastasis by inducing EMT.

(Fig. 2) [111]. However, further studies are required to fully understand the unique molecular and cellular pathogenic mechanisms of $F$. nucleatum in OSCC tumorigenesis. Although studies have shown that OPMDs are enriched with Fusobacteria [64, 65], direct evidence that this colonisation increases the risk of malignant transformation is absent. There is a need for longitudinal follow-up studies of OPMDs to establish if those enriched with $F$. nucleatum are at an increased risk of developing OSCC independent of smoking, alcohol and HPV status. Advancement of omics technologies could facilitate novel insights in this area. Moreover, further research is necessary to confirm recent findings that F. nucleatum infection is associated with a better clinical outcome in OSCC. Validation of F. nucleatum as a prognostic biomarker could have major implications for future oral cancer screening and management.

\footnotetext{
Abbreviations

CRC: colorectal cancer; EMT: epithelial-mesenchymal transition; F. nucleatum: Fusobacterium nucleatum; FadA: Fusobacterium adhesin A; Fap2: fibroblast activation protein 2; Gal-GalNAc: galactose/Nacetylgalactosamine; HPV: human papilloma virus; IL: interleukin; JAK: Janus Kinase; LPS: lipopolysaccharide; MMP: matrix metalloproteinase; MYC: myelocytomatosis; MYD88: Myeloid differentiation primary response 88 NF-KB: nuclear factor kappa-light-chain-enhancer of activated B cells; NGS: next generation sequencing; NK cell: Natural killer cell; OPMD: oral potentially malignant disorder; OSCC: oral squamous cell carcinomaPNApeanut agglutinin; ROS: reactive oxygen species; STAT: signal transducer and activator of transcription; TIGIT: T cell immunoreceptor with Ig and ITIM domains; TLR: Toll-like receptor; TNF: tumour necrosis factor; WNT: Wingless-type MMTV integration site family member; ZEB: Zinc finger E-box-binding homeobox
}

Acknowledgements

None.

Authors' contributions

EMcl drafted the initial manuscript; GL, FL, SC, JJ reviewed and revised the manuscript. All authors reviewed and approved the final manuscript.

Funding

No specific funding was received for this study.

Availability of data and materials

Not applicable.

\section{Declarations}

Ethics approval and consent to participate

Not applicable.

Consent for publication

Not applicable.

\section{Competing interests}

The authors declare they have no competing interests.

\section{Author details}

${ }^{1}$ Patrick G Johnson Centre for Cancer Research, Queen's University Belfast, Belfast, Northern Ireland, UK. ${ }^{2}$ Centre for Public Health, School of Medicine, Dentistry and Biomedical Sciences, Queen's University Belfast, Belfast, Northern Ireland, UK. ${ }^{3}$ Precision Medicine Centre of Excellence, Health Sciences Building, Queen's University Belfast, Belfast, Northern Ireland, UK.

${ }^{4}$ Wellcome-Wolfson Institute for Experimental Medicine, Queen's University Belfast, Belfast, Northern Ireland, UK. ${ }^{5}$ Northern Ireland Biobank, Health Sciences Building, Queen's University Belfast, Belfast, Northern Ireland, UK.

Received: 17 February 2021 Accepted: 21 October 2021

Published online: 13 November 2021

\section{References}

1. Bray F, Ferlay J, Soerjomataram I, Siegel RL, Torre LA, Jemal A. Global cancer statistics 2018: GLOBOCAN estimates of incidence and mortality worldwide for 36 cancers in 185 countries [published correction appears in CA Cancer J Clin. 2020 Jul;70(4):313]. CA Cancer J Clin 2018;68(6):394-424, DOl: https:// doi.org/10.3322/caac.21492.

2. Warnakulasuriya S, Kujan O, Aguirre-Urizar JM, Bagan JV, González-Moles MÁ, Kerr AR, et al. Oral potentially malignant disorders: a consensus report from an international seminar on nomenclature and classification, convened by the WHO collaborating Centre for Oral Cancer. Oral Dis. 2020. https://doi. org/10.1111/odi13704 Epub ahead of print.

3. Bagnardi V, Rota M, Botteri E, Tramacere I, Islami F, Fedirko V, et al. Alcohol consumption and site-specific cancer risk: a comprehensive dose-response meta-analysis. Br J Cancer. 2015;112(3):580-93. https://doi.org/10.1038/bjc.2 014.579 .

4. Myers J, Elkins T, Roberts D, Byers R. Squamous cell carcinoma of the tongue in young adults: increasing incidence and factors that predict treatment outcomes. Otolaryngol Head Neck Surg. 2000;122(1):44-51. https://doi.org/10.1016/S0194-5998(00)70142-2.

5. Kruse AL, Bredell M, Grätz KW. Oral squamous cell carcinoma in nonsmoking and non-drinking patients. Head \& Neck Oncology. 2010;2(1):24. https://doi.org/10.1186/1758-3284-2-24

6. De Martel C, Georges D, Bray F, Ferlay J, Clifford GM. Global burden of cancer attributable to infections in 2018: a worldwide incidence analysis. The Lancet. 2020;2(8):180-90.

7. Leemans CR, Snijders PJF, Brakenhoff RH. The molecular landscape of head and neck cancer. Nat Rev Cancer. 2018 May;18(5):269-82. https://doi.org/1 $0.1038 /$ nrc.2018.11.

8. Chow L. Head and neck Cancer. N Engl J Med. 2020;382(1):60-72. https:// doi.org/10.1056/NEJMra1715715.

9. Mark Welch JL, Ramírez-Puebla ST, Borisy GG. Oral microbiome geography: micron-scale habitat and niche. Cell Host Microbe. 2020:28(2):160-8. https:// doi.org/10.1016/j.chom.2020.07.009. 
10. Könönen E, Gursoy M, Gursoy UK. Periodontitis: a multifaceted disease of tooth-supporting tissues. J Clin Med. 2019;8(8):1135. Published 2019 Jul 31.

11. Hajishengallis G, Lambris JD. Complement and dysbiosis in periodontal disease. Immunobiology. 2012;217(11):1111-6. https://doi.org/10.1016/j. imbio.2012.07.007.

12. Curtis MA, Diaz PI, Van Dyke TE. The role of the microbiota in periodontal disease. Periodontology 2000. 2020;83(1):14-25.

13. Elinav E, Nowarski R, Thaiss C, Hu B, Jin C, Flavell R. Inflammation-induced cancer: crosstalk between tumours, immune cells and microorganisms. Nat Rev Cancer. 2014;13(11):759-71. https://doi.org/10.1038/nrc3611.

14. Ye L, Jiang Y, Liu W, Tao H. Correlation between periodontal disease and oral cancer risk: a meta-analysis. J Cancer Res Ther. 2016;12(8):237-40. https://doi.org/10.4103/0973-1482.200746.

15. Tezal M, Sullivan MA, Hyland A, Marshall JR, Stoler D, Reid ME, et al. Chronic periodontitis and the incidence of head and neck squamous cell carcinoma. Cancer Epidemiol Biomark Prev. 2009;18(9):2406-12. https://doi.org/10.11 58/1055-9965.EPI-09-0334.

16. Tezal M, Sullivan MA, Reid ME, Marshall JR, Hyland A, Loree T, et al. Chronic periodontitis and the risk of tongue cancer. Arch Otolaryngol Head Neck Surg. 2007;133(5):450-4. https://doi.org/10.1001/archotol.133.5.450.

17. Tezal M, Grossi S, Genco R. Is periodontitis associated with oral neoplasms? J Periodontol. 2005;76(3):406-10. https://doi.org/10.1902/jop.2005.76.3.406.

18. Kostic AD, Chun E, Robertson L, Glickman JN, Gallini CA, Michaud M, et al. Fusobacterium nucleatum potentiates intestinal tumorigenesis and modulates the tumor immune microenvironment. Cell Host Microbe. 2013; 14(2):207-15. https://doi.org/10.1016/j.chom.2013.07.007.

19. Castellarin M, Warren RL, Freeman JD, Dreolini L, Krzywinski M, Strauss J, et al. Fusobacterium nucleatum infection is prevalent in human colorectal carcinoma. Genome Res. 2012;22(2):299-306. https://doi.org/10.1101/gr.12 6516.111.

20. Brennan CA, Garrett WS. Fusobacterium nucleatum - symbiont, opportunist and oncobacterium. Nat Rev Microbiol. 2019;17(3):156-66. https://doi.org/ 0.1038/s41579-018-0129-6.

21. Kolenbrander PE, Andersen RN, Blehert DS, Egland PG, Foster JS, Palmer RJ Jr. Communication among oral bacteria. Microbiol Mol Biol Rev. 2002;66(3): 486-505. https://doi.org/10.1128/MMBR.66.3.486-505.2002.

22. Han YW, Ikegami A, Rajanna C, Kawsar HI, Zhou Y, Li M, et al. Identification and characterization of a novel adhesin unique to oral fusobacteria. J Bacteriol. 2005;187(15):5330-40. https://doi.org/10.1128/JB.187.15.5330-534 0.2005 .

23. Coppenhagen-Glazer S, Sol A, Abed J, Naor R, Zhang X, Han YW, et al. Fap2 of Fusobacterium nucleatum is a galactose-inhibitable adhesin involved in coaggregation, cell adhesion, and preterm birth. Infect Immun. 2015;83(3): 1104-13. https://doi.org/10.1128/IAl.02838-14.

24. Ito M, Kanno S, Nosho K, Sukawa Y, Mitsuhashi K, Kurihara H, et al. Association of Fusobacterium nucleatum with clinical and molecular features in colorectal serrated pathway. Int J Cancer. 2015;137(6):1258-68. https://doi. org/10.1002/ijc.29488.

25. Yu J, Chen $Y$, Fu X, Zhou X, Peng Y, Shi L, et al. Invasive Fusobacterium nucleatum may play a role in the carcinogenesis of proximal colon cancer through the serrated neoplasia pathway. Int J Cancer. 2016;139(6):1318-26. https://doi.org/10.1002/ijc.30168.

26. Flanagan L, Schmid J, Ebert M, Soucek P, Kunicka T, Liska V, et al. Fusobacterium nucleatum associates with stages of colorectal neoplasia development, colorectal cancer and disease outcome. Eur J Clin Microbiol Infect Dis. 2014;33(8):1381-90. https://doi.org/10.1007/s10096-014-2081-3.

27. Sun Y, An QM, Tian XY, Wang ZL, Guan XY, Dong B, et al. Fusobacterium nucleatum infection is correlated with tumor metastasis and postoperative survival of colorectal cancer patients in China. Transl Cancer Res. 2016;5(5): 579-88. https://doi.org/10.21037/tcr.2016.10.45.

28. Yamaoka Y, Suehiro Y, Hashimoto S, Hoshida T, Fujimoto M, Watanabe M, et al. Fusobacterium nucleatum as a prognostic marker of colorectal cancer in a Japanese population. J Gastroenterol. 2018;53(4):517-24. https://doi. org/10.1007/s00535-017-1382-6.

29. Gethings-Behncke C, Coleman H, Jordao H, Longley D, Crawford C, Murray $\mathrm{L}$, Kunzmann A. Fusobacterium nucleatum in the colorectum and its association with cancer risk and survival: a systematic review and metaanalysis. Cancer Epidemiol Biomark Prev 2020; 29(3), Fusobacterium nucleatumin the Colorectum and Its Association with Cancer Risk and Survival: A Systematic Review and Meta-analysis, 29, 3, 29548, DOl: https:// doi.org/10.1158/1055-9965.EPI-18-1295.
30. Wu N, Yang X, Zhang R, Li J, Xiao X, Hu Y, et al. Dysbiosis signature of fecal microbiota in colorectal cancer patients. Microb Ecol. 2013;66(2):462-70. https://doi.org/10.1007/s00248-013-0245-9.

31. Amitay EL, Werner S, Vital M, Pieper DH, Höfler D, Gierse IJ, et al. Fusobacterium and colorectal cancer: causal factor or passenger? Results from a large colorectal cancer screening study. Carcinogenesis. 2017;38(8): 781-8. https://doi.org/10.1093/carcin/bgx053.

32. Yu J, Feng Q, Wong SH, Zhang D, Liang QY, Qin Y, et al. Metagenomic analysis of faecal microbiome as a tool towards targeted non-invasive biomarkers for colorectal cancer. Gut. 2017;66(1):70-8. https://doi.org/10.113 6/gutjnl-2015-309800.

33. Mitsuhashi K, Nosho K, Sukawa Y, Matsunaga Y, Ito M, Kurihara H, et al. Association of Fusobacterium species in pancreatic cancer tissues with molecular features and prognosis. Oncotarget. 2015;6(9):7209-20. https:// doi.org/10.18632/oncotarget.3109.

34. Yamamura K, Baba Y, Nakagawa S, Mima K, Miyake K, Nakamura K, et al. Human microbiome Fusobacterium nucleatum in esophageal cancer tissue is associated with prognosis. Clin Cancer Res. 2016;22(22):5574-81. https://doi. org/10.1158/1078-0432.CCR-16-1786.

35. Yamamura K, Baba Y, Miyake K, Nakamura K, Shigaki H, Mima K, et al. Fusobacterium nucleatum in gastroenterological cancer: evaluation of measurement methods using quantitative polymerase chain reaction and a literature review. Oncol Lett. 2017;14(6):6373-8. https://doi.org/10.3892/ol.2 017.7001.

36. Hsieh YY, Tung SY, Pan HY, Yen CW, Xu HW, Lin YJ, et al. Increased abundance of Clostridium and Fusobacterium in gastric microbiota of patients with gastric cancer in Taiwan. Sci Rep. 2018;8(1):158. https://doi. org/10.1038/s41598-017-18596-0.

37. Parhi L, Alon-Maimon T, Sol A, Nejman D, Shhadeh A, Fainsod-Levi T, et al. Breast cancer colonization by Fusobacterium nucleatum accelerates tumor growth and metastatic progression. Nat Commun. 2020;11(1):3259. https:// doi.org/10.1038/s41467-020-16967-2.

38. Mima K, Nishihara R, Qian ZR, Cao Y, Sukawa Y, Nowak JA, et al. Fusobacterium nucleatum in colorectal carcinoma tissue and patient prognosis. Gut. 2016;65(12):1973-80. https://doi.org/10.1136/gutjnl-2015-31 0101

39. Yu T, Guo F, Yu Y, et al. Fusobacterium nucleatum promotes chemoresistance to colorectal cancer by modulating autophagy. Cell. 2017; 170(3):548-563.e16.

40. Wei Z, Cao S, Liu S, Yao Z, Sun T, Li Y, et al. Could gut microbiota serve as prognostic biomarker associated with colorectal cancer patients' survival? A pilot study on relevant mechanism. Oncotarget. 2016;7(29):46158-72. https://doi.org/10.18632/oncotarget.10064.

41. Lee DW, Han SW, Kang JK, Bae JM, Kim HP, Won JK, et al. Association between Fusobacterium nucleatum, pathway mutation, and patient prognosis in colorectal cancer. Ann Surg Oncol. 2018;25(11):3389-95. https://doi.org/10.1245/s10434-018-6681-5.

42. de Carvalho AC, de Mattos PL, Datorre JG, dos Santos W, Berardinelli GN, Matsushita MM, et al. Microbiota profile and impact of Fusobacterium nucleatum in colorectal cancer patients of Barretos cancer hospital. Front Oncol. 2019:9:813. https://doi.org/10.3389/fonc.2019.00813.

43. Kunzmann AT, Proença MA, Jordao HW, et al. Fusobacterium nucleatum tumor DNA levels are associated with survival in colorectal cancer patients. Eur J Clin Microbiol Infect Dis. 2019;38(10):1891-9. https://doi.org/10.1007/s1 0096-019-03649-1.

44. Chen Y, Lu Y, Ke Y, Li Y. Prognostic impact of the Fusobacterium nucleatum status in colorectal cancers. Medicine (Baltimore). 2019;98(39):e17221.

45. Yan X, Liu L, Li H, Qin H, Sun Z. Clinical significance of Fusobacterium nucleatum, epithelial-mesenchymal transition, and cancer stem cell markers in stage III/IV colorectal cancer patients. OncoTargets and therapy. 2017;10: 5031-46. https://doi.org/10.2147/OTT.S145949.

46. Bullman S, Pedamallu CS, Sicinska E, Clancy TE, Zhang X, Cai D, et al. Analysis of Fusobacterium persistence and antibiotic response in colorectal cancer. Science. 2017;358(6369):1443-8. https://doi.org/10.1126/science.aa 15240.

47. Komiya $Y$, Shimomura $Y$, Higurashi $T$, Sugi $Y$, Arimoto J, Umezawa $S$, et al. Patients with colorectal cancer have identical strains of Fusobacterium nucleatum in their colorectal cancer and oral cavity. Gut. 2018;68(7):1335-7. https://doi.org/10.1136/gutjnl-2018-316661.

48. Perera M. Al-hebshi Nezar Noor, Speicher DJ, Perera I. Johnson NW Emerging role of bacteria in oral carcinogenesis: a review with special 
reference to perio-pathogenic bacteria Journal of Oral Microbiology. 2016; 8(1):10. https://doi.org/10.3402/jom.v8.32762

49. Hooper SJ, Crean SJ, Lewis MAO, Spratt DA, Wade WG, Wilson MJ. Viable bacteria present within oral squamous cell carcinoma tissue. J Clin Microbiol. 2006;44(5):1719-25. https://doi.org/10.1128/JCM.44.5.1719-1725.2006.

50. Pushalkar S, Mane SP, Ji X, Li Y, Evans C, Crasta OR, et al. Microbial diversity in saliva of oral squamous cell carcinoma. FEMS Immunol Med Microbiol. 2011;61(3):269-77. https://doi.org/10.1111/j.1574-695X.2010.00773.x.

51. Pushalkar S, Ji X, Li Y, Estilo C, Yegnanarayana R, Singh B, et al. Comparison of oral microbiota in tumor and non-tumor tissues of patients with oral squamous cell carcinoma. BMC Microbiol. 2012;12(1):144. https://doi.org/1 0.1186/1471-2180-12-144.

52. Schmidt BL, Kuczynski J, Bhattacharya A, Huey B, Corby PM, Queiroz EL, et al. Change in abundance of oral microbiota associated with oral cancer. PLoS One. 2014:9e98741

53. Nagy K, Sonkodi I, Szöke I, Nagy E, Newman H. The microflora associated with human oral carcinomas. Oral Oncol. 1998;34:304-8.

54. Al-Hebshi NN, Nasher AT, Idris AM, Chen T. Robust species taxonomy assignment algorithm for $16 \mathrm{~S}$ rRNA NGS reads: application to oral carcinoma samples. Journal of Oral Microbiology. 2015;7(1):10. https://doi. org/10.3402/jom.v7.28934.

55. Al-hebshi N, Nasher AT, Maryoud MY, Homeida HE, Chen T, Idris AM, et al. Inflammatory bacteriome featuring Fusobacterium nucleatum and Pseudomonas aeruginosa identified in association with oral squamous cell carcinoma. Sci Rep. 2017;7(1):1834. https://doi.org/10.1038/s41598-017-02079-3.

56. Zhang L, Liu Y, Zheng HJ, Zhang CP. The oral microbiota may have influence on oralc. Front Cell Infect Microbiol. 2020;9:476. https://doi.org/1 0.3389/fcimb.2019.00476.

57. Zhao H, Chu M, Huang Z, Yang X, Ran S, Hu B, et al. Variations in oral microbiota associated with oral cancer. Sci Rep. 2017;7(1):11773. https://doi. org/10.1038/s41598-017-11779-9.

58. Guerrero-Preston R, White JR, Godoy-Vitorino F, Rodríguez-Hilario A, Navarro K, González H, et al. High-resolution microbiome profiling uncovers Fusobacterium nucleatum, lactobacillus gasseri/johnsonii, and lactobacillus vaginalis associated to oral and oropharyngeal cancer in saliva from HPV positive and HPV negative patients treated with surgery and chemoradiation. Oncotarget. 2017;8(67):110931-48. https://doi.org/10.18632/oncota rget.20677.

59. Perera M, Al-hebshi NN, Perera I, Ipe D, Ulett GC, Speicher DJ, et al. Inflammatory Bacteriome and Oral squamous cell carcinoma. J Dent Res. 2018;97(6):725-32. https://doi.org/10.1177/0022034518767118.

60. Hsiao JR, Chang CC, Lee WT, Huang CC, Ou CY, Tsai ST, et al. The interplay between oral microbiome, lifestyle factors and genetic polymorphisms in the risk of oral squamous cell carcinoma. Carcinogenesis. 2018;39(6):778-87. https://doi.org/10.1093/carcin/bgy053.

61. Chang C, Geng F, Shi X, Li Y, Zhang X, Zhao X, et al. The prevalence rate of periodontal pathogens and its association with oral squamous cell carcinoma. Appl Microbiol Biotechnol. 2018;103(3):1393-404. https://doi. org/10.1007/s00253-018-9475-6. [Epub ahead of print].

62. Yost S, Stashenko P, Choi Y, Kukuruzinska M, Genco CA, Salama A, et al. Increased virulence of the oral microbiome in oral squamous cell carcinoma revealed by metatranscriptome analyses. Int J Oral Sci. 2018;10(4):32. https:// doi.org/10.1038/s41368-018-0037-7.

63. Bronzatoa JD, Bomfim RA, Edwards DH, Crouch D, Hector MP, et al. Detection of Fusobacterium in oral and head and neck cancer samples: a systematic review and meta-analysis. Arch Oral Biol. 2020;112:104669. https://doi.org/10.1016/j.archoralbio.2020.104669.

64. Amer A, Galvin S, Healy CM, Moran GP. The microbiome of potentially malignant oral leukoplakia exhibits enrichment for Fusobacterium, Leptotrichia, Campylobacter, and Rothia species. Front Microbiol. 2017;8:2391. https://doi.org/10.3389/fmicb.2017.02391.

65. Decsi G, Soki J, Pap B, Dobra G, Harmati M, Kormondi S, et al. Chicken or the egg: microbial alterations in biopsy samples of patients with oral potentially malignant disorders. Pathol Oncol Res. 2019;25(3):1023-33. https://doi.org/10.1007/s12253-018-0457-x.

66. Neuzillet C, Marchais M, Vacher S, Hilmi M, Schnitzler A, Meseure D, et al. Prognostic value of intratumoral Fusobacterium nucleatum and association with immune-related gene expression in oral squamous cell carcinoma patients. Sci Rep. 2021;11(1):7870. https://doi.org/10.1038/s41598-021-86816-9.

67. Chen Z, Wong PY, Ng CWK, Lan L, Fung S, Li JW, et al. The intersection between oral microbiota, host gene methylation and patient outcomes in head and neck squamous cell carcinoma. Cancers. 2020;12(11):3425. https:// doi.org/10.3390/cancers12113425.

68. Gallimidi AB, Fischman S, Revach B, Bulvik R, Maliutina A, Rubinstein AM, et al. Periodontal pathogens Porphyromonas gingivalis and Fusobacterium nucleatum promote tumor progression in an oral-specific chemical carcinogenesis model. Oncotarget. 2015;6(26):22613-23. https://doi.org/10.1 8632/oncotarget.4209.

69. Harrandah A, Chukkapalli S, Bhattacharyya I, Progulske-Fox A, Chan E. Fusobacteria modulate oral carcinogenesis and promote cancer progression. J Oral Microbiology. 2020;31(1):1849493. https://doi.org/10.1 080/20002297.2020.1849493.

70. Abed J, Emgård JEM, Zamir G, Faroja M, Almogy G, Grenov A, et al. Fap2 mediates Fusobacterium nucleatum colorectal adenocarcinoma enrichment by binding to tumor-expressed gal-GalNAc. Cell Host Microbe. 2016;20(2): 215-25. https://doi.org/10.1016/j.chom.2016.07.006.

71. Abed J, Maalouf N, Parhi L, Chaushu S, Mandelboim O, Bachrach G. Tumor targeting by Fusobacterium nucleatum: a pilot study and future perspectives. Frontiers in Cellular and Infectious Microbiology. 2017;7:295. https://doi. org/10.3389/fcimb.2017.00295.

72. Mazumdar S, SenGupta SK, Param R, Sinha SN. Binding pattern of eight different lectins in healthy subjects and patients with dysplastic and malignant lesions of the oral cavity. Int J Oral Maxillofac Surg. 1993;22(5): 301-5. https://doi.org/10.1016/S0901-5027(05)80521-1.

73. Huang R, Li M, Gregory RL. Bacterial interactions in dental biofilm. Virulence. 2011;2(5):435-44. https://doi.org/10.4161/viru.2.5.16140.

74. Katz J, Onate MD, Pauley KM, Bhattacharyya I, Cha S. Presence of Porphyromonas gingivalis in gingival squamous cell carcinoma. International Journal of Oral Science. 2011;3(4):209-15. https://doi.org/10.4248/IJOS11075.

75. Olsen I, Yilmaz Ö. Possible role of Porphyromonas gingivalis in orodigestive cancers. J Oral Microbiol. 2019;11(1):1563410. https://doi.org/10.1080/200022 97.2018.1563410.

76. Alnuaimia AD, Wiesenfeld D, O'Brien-Simpson NM, Reynolds EC, McCullough MJ. Oral Candida colonization in oral cancer patients and its relationship with traditional risk factors of oral cancer: a matched case-control study. Oral Oncol. 2015;51(1):139-45. https://doi.org/10.1016/j.oraloncology.2 014.11.008.

77. Bor B, Cen L, Agnello M, Shi W, He X. Morphological and physiological changes induced by contact-dependent interaction between Candida albicans and Fusobacterium nucleatum. Sci Rep. 2016;6(1):27956. https://doi. org/10.1038/srep27956.

78. Rubinstein MR, Wang X, Liu W, Hao Y, Cai G, Han YW. Fusobacterium nucleatum promotes colorectal carcinogenesis by modulating E-cadherin/ $\beta$ catenin signalling via its FadA adhesin. Cell Host Microbe. 2013;14(2):195206. https://doi.org/10.1016/j.chom.2013.07.012.

79. Ma C-T, Luo H-S, Gao F, Tang Q-C, Chen W. Fusobacterium nucleatum promotes the progression of colorectal cancer by interacting with E-cadherin. Oncol Lett. 2018;16(2):2606-12. https://doi.org/10.3892/ol.2018.8947.

80. Fardini $Y$, Wang X, Témoin S, Nithianantham S, Lee D, Shoham M, et al. Fusobacterium nucleatum adhesin FadA binds vascular-endothelial cadherin and alters endothelial integrity. Mol Microbiol. 2011;82(6):1468-80. https:// doi.org/10.1111/j.1365-2958.2011.07905.x.

81. Rubinstein MR, Baik JE, Lagana SM, et al. Fusobacterium nucleatum promotes colorectal cancer by inducing Wnt/B-catenin modulator Annexin A1. EMBO Rep. 2019;20(4):e47638.

82. Yang $Y$, Weng $W$, Peng J, et al. Fusobacterium nucleatum increases proliferation of colorectal cancer cells and tumor development in mice by activating tolllike receptor 4 signalling to nuclear factor- $\mathrm{kB}$, and up-regulating expression of MicroRNA-21. Gastroenterology. 2017;152(4):851-66.

83. Wu Y, Wu J, Chen T, Li Q, Peng W, Li H, et al. Fusobacterium nucleatum potentiates intestinal tumorigenesis in mice via a toll-like receptor 4/p21activated kinase 1 cascade. Dig Dis Sci. 2018;63(5):1210-8. https://doi.org/1 0.1007/s10620-018-4999-2.

84. Geng F, Zhang Y, Lu A, Zhang S, Pan Y. Fusobacterium nucleatum caused DNA damage and promoted cell proliferation by the Ku70/p53 pathway in oral cancer cells. DNA and Cell Biology. 2020;39(1).

85. Kang W, Jia Z, Tang D, Zhang Z, Gao H, He K, et al. Fusobacterium nucleatum facilitates apoptosis, ROS generation, and inflammatory cytokine production by activating AKT/MAPK and NF-KB signaling pathways in human gingival fibroblasts. Oxidative Med Cell Longev. 2019;2019:168197222. https://doi.org/10.1155/2019/1681972. 
86. Tang B, Wang K, Jia YP, Zhu P, Fang Y, Zhang ZJ, et al. Fusobacterium nucleatum-induced impairment of autophagic flux enhances the expression of proinflammatory cytokines via ROS in Caco-2 cells. PLoS One. 2016;11(11): e0165701. https://doi.org/10.1371/journal.pone.0165701.

87. Guijarro-Muñoz I, Compte M, Álvarez-Cienfuegos A, Álvarez-Vallina L, Sanz L. Lipopolysaccharide activates toll-like receptor 4 (TLR4)-mediated NF-KB signaling pathway and proinflammatory response in human pericytes. J Biol Chem. 2014;289(4):2457-68. https://doi.org/10.1074/jbc.M113.521161.

88. Zu Y, Ping W, Deng T, Zhang N, Fu X, Sun W. Lipopolysaccharide-induced tolllike receptor 4 signaling in esophageal squamous cell carcinoma promotes tumor proliferation and regulates inflammatory cytokines expression. Dis Esophagus. 2017;30(2):1-8. https://doi.org/10.1111/dote.12466.

89. Quah SY, Bergenholtz G, Tan KS. Fusobacterium nucleatum induces cytokine production through toll-like-receptor-independent mechanism. Int Endod J. 2013;47(6):550-9. https://doi.org/10.1111/iej.12185.

90. Mima K, Sukawa Y, Nishihara R, Qian ZR, Yamauchi M, Inamura K, et al. Fusobacterium nucleatum and T-cells in colorectal carcinoma. JAMA oncology. 2015;1(5):653-61. https://doi.org/10.1001/jamaoncol.2015.1377.

91. Chen T, Li Q, Zhang X, Long R, Wu Y, Wu J, et al. TOX expression decreases with progression of colorectal cancers and is associated with CD4 T-cell density and Fusobacterium nucleatum infection. Hum Pathol. 2018;79:93101. https://doi.org/10.1016/j.humpath.2018.05.008.

92. Shenker BJ, Datar S. Fusobacterium nucleatum inhibits human T-cell activation by arresting cells in the mid-G1 phase of the cell cycle. Infect Immun. 1995;63(12):4830-6. https://doi.org/10.1128/iai.63.12.4830-4836.1995.

93. Gur C, Ibrahim Y, Isaacson B, Yamin R, Abed J, Gamliel M, et al. Binding of the Fap2 protein of Fusobacterium nucleatum to human inhibitory receptor TIGIT protects tumors from immune cell attack. Immunity. 2015;42(2):34455. https://doi.org/10.1016/j.immuni.2015.01.010.

94. Kaplan CW, Ma X, Paranjpe A, et al. Fusobacterium nucleatum outer membrane proteins Fap2 and RadD induce cell death in human lymphocytes. Infect Immun. 2010;78(11):4773-8.

95. Chen T, Li Q, Wu J, Wu Y, Peng W, Li H, et al. Fusobacterium nucleatum promotes $\mathrm{M} 2$ polarization of macrophages in the microenvironment of colorectal tumours via a TLR4-dependent mechanism. Cancer Immunol Immunother. 2018 Oct;67(10):1635-46. https://doi.org/10.1007/s00262-01 8-2233-x.

96. Kessenbrock K, Plaks V, Werb Z. Matrix metalloproteinases: regulators of the tumor microenvironment. Cell. 2010;141(1):52-67. https://doi.org/10.1016/j. cell.2010.03.015.

97. Uitto V-J, Baillie D, Wu Q, Gendron R, Grenier D, Putnins EE, et al. Fusobacterium nucleatum increases collagenase 3 production and migration of epithelial cells. Infect Immun. 2005;73(2):1171-9. https://doi.org/10.1128/ |Al.73.2.1171-1179.2005.

98. Inaba H, Sugita H, Kuboniwa M, Iwai S, Hamada M, Noda T, et al. Porphyromonas gingivalis promotes invasion of oral squamous cell carcinoma through induction of proMMP9 and its activation. Cell Microbiol. 2014;16(1):131-45. https://doi.org/10.1111/cmi.12211.

99. Inaba H, Amano A, Lamont RJ, Murakami Y. Involvement of proteaseactivated receptor 4 in over-expression of matrix metalloproteinase 9 induced by Porphyromonas gingivalis. Med Microbiol Immunol. 2015;204(5): 605-12. https://doi.org/10.1007/s00430-015-0389-y.

100. Ha NH, Woo BH, Kim da J, Ha ES, Choi JI, Kim SJ, et al. Prolonged and repetitive exposure to Porphyromonas gingivalis increases aggressiveness of oral cancer cells by promoting acquisition of cancer stem cell properties. Tumour Biol 2015;36:9947-9960, 12, DOl: https://doi.org/10.1007/s13277-01 5-3764-9.

101. Krisanaprakornkit S, lamaroon A. Epithelial-mesenchymal transition in Oral squamous cell carcinoma. ISRN Oncol. 2012;2012:681469-10. https://doi. org/10.5402/2012/681469.

102. Their JP. Epithelial-mesenchymal transitions in tumor progression. Nat Rev Cancer. 2002;2(6):442-54. https://doi.org/10.1038/nrc822.

103. Abdulkareem AA, Shelton RM, Landini G, Cooper PR, Milward MR. Periodontal pathogens promote epithelial-mesenchymal transition in oral squamous carcinoma cells in vitro. Cell Adhes Migr. 2018;12(2):127-37. https://doi.org/10.1080/19336918.2017.1322253.

104. Zhang S, Li C, Liu J, Geng F, Shi X, Li Q, et al. Fusobacterium nucleatum promotes epithelial-mesenchymal transition through regulation of the IncRNA MIR4435-2HG/miR-296-5p/Akt2/SNAl1 signaling pathway. FEBS J. 2020;287(18):4032-47. https://doi.org/10.1111/febs.15233.
105. Baud J, Varon C, Chabas S, Chambonnier L, Darfeuille F, Staedel C. Helicobacter pylori initiates a mesenchymal transition through ZEB1 in gastric epithelial cells. PLoS One. 2013;8(4):e60315. https://doi.org/10.1371/ journal.pone.0060315.

106. Kamarajan P, Ateia I, Shin JM, Fenno JC, le C, Zhan L, et al. Periodontal pathogens promote cancer aggressivity via TLR/MyD88 triggered activation of integrin/FAK signaling that is therapeutically reversible by a probiotic bacteriocin. PLoS Pathog. 2020;16(10):e1008881. https://doi.org/10.1371/ journal.ppat.1008881.

107. Nguyen T, Brody H, Lin GH, Range H, Kuraji R, Ye C, et al. Probiotics, including nisin-based probiotics, improve clinical and microbial outcomes relevant to oral and systemic diseases. Periodontol 2000. 2020;82(1):173-185.

108. Liu PF, Shi W, Zhu W, Smith JW, Hsieh SL, Gallo RL, et al. Vaccination targeting surface FomA of Fusobacterium nucleatum against bacterial coaggregation: implication for treatment of periodontal infection and halitosis. Vaccine. 2010;28(19):3496-505. https://doi.org/10.1016/j.vaccine.2010.02.047.

109. Guo SH, Wang HF, Nian ZG, Wang YD, Zeng QY, Zhang G. Immunization with alkyl hydroperoxide reductase subunit $C$ reduces Fusobacterium nucleatum load in the intestinal tract. Sci Rep. 2017;7(1):10566. https://doi. org/10.1038/s41598-017-11127-x.

110. Gopinath D, Wie CC, Banerjee M, Thangavelu L, Kumar R P, Nallaswamy D, et al. Compositional profile of mucosal bacteriome of smokers and smokeless tobacco users. Clin Oral Invest. 2021. https://doi.org/10.1007/ s00784-021-04137-7.

111. Fulbright LE, Ellermann M, Arthur JC. The microbiome and the hallmarks of cancer. PLoS Pathog. 2017;13(9):e1006480. https://doi.org/10.1371/journal. ppat.1006480.

\section{Publisher's Note}

Springer Nature remains neutral with regard to jurisdictional claims in published maps and institutional affiliations.
Ready to submit your research? Choose BMC and benefit from:

- fast, convenient online submission

- thorough peer review by experienced researchers in your field

- rapid publication on acceptance

- support for research data, including large and complex data types

- gold Open Access which fosters wider collaboration and increased citations

- maximum visibility for your research: over $100 \mathrm{M}$ website views per year

At BMC, research is always in progress.

Learn more biomedcentral.com/submissions 